\title{
Principles of Creation of Local Network for Lightning Discharge Observations on Active Volcanoes of Kamchatka Peninsula
}

\author{
Evgeniy Malkin*1, Gennadiy Druzhin $^{1}$, Pavel Firstov ${ }^{2}$, Nina Cherneva ${ }^{l}$, Vladimir Uvarov ${ }^{l}$, \\ Dmitriy Sannikov ${ }^{l}$ and Ivan Stasiy ${ }^{l}$ \\ ${ }^{1}$ Institute of Cosmophysical Research and Radio Wave Propagation FEB RAS, Russia \\ ${ }^{2}$ Kamchatka Branch of the Geophysical Survey RAS, Russia
}

\begin{abstract}
To investigate the thunderstorm activity according to electromagnetic radiation recorded data, it is necessary to create a local network which will be located near the Klyuchevskaya Sopka, Shiveluch and Tolbachik volcanoes. VLF direction finders, electric field sensors, synchronization system, auxiliary equipment will be installed at observation points. Based on the analysis of waveforms and spectral-temporal characteristics, the locations of radiation sources, their belonging to a certain class will be determined. The parameters, by which volcanic lightning differs from ordinary ones, will be determined. Examples of electromagnetic radiation occurring near the Shiveluch volcano are given. The information can be further used to monitor thunderstorm and volcanic activities. $^{* *}$
\end{abstract}

\section{Introduction}

Kamchatka is a land of spitfier mountains. In spite of this poetry, volcano fire breath is very hazardous. For a remote infrastructure, for people and especially for the flights, ash and gas ejections, forming eruptive clouds (EC), are the most dangerous during an eruption. Consequently, EC propagation monitoring allows us to make fast alerts. The main methods tracing EC propagation are direct observations of electromagnetic waves (EMW) in visible and infrared spectra. However, such a type of observations is not always possible, for example, when the cloud cover is thick. During explosive eruptions of volcanoes, magma fragmentation (destruction) takes place in the result of sharp release of lighospheric pressure. Later, the ash-gas mixture forms an eruptive column and then an EC. This process is accompanied by dejecta electrification and generation of electric discharges of different intensity. Location of these charges gives us a notion on EC spatial location even when the cloud cover is thick $[7,9]$.

\footnotetext{
*Corresponding author: malkin@ikir.ru

**The work was carried out according to the Subject AAAA-A17-117080110043-4 and supported by RFBR, Grant No. 19-05-00543.
} 


\section{Existing methods}

The main method to detect high-current electric discharges of atmospheric origin is the variate-difference one. It consists in accurate determination of the delay time between the same pulse records at spaced basic stations followed by hyperbolas set reconstruction and search for their intersection. Basic observation sites form a lightning location network. The most known representative of such a network is the NLDN (National Lightning Detection Network) located in the USA. Lightning discharges are located with TOA (Time Of Arrival) algorithm [1].

Within the framework of this algorithm, time is fixed when the maximum of signal «ground» component first half-wave is achieved. The signal is recorded in the frequency band of 1-400 kHz. Within the inner zone of this network, the accuracy of lightning discharge location is $\sim 500$. The World Wide Lightning Location Network (WWLLN) is similar in method but is different in realization. This network also refers to variatedifference locating systems (VDLS) but the method to determine the time delay obeys the TOGA algorithm (Time Of Group Arrival). The essence of this method is measurement of signal group delay recorded in the frequency band of 6-22 kHz. Fig. 1b shows lightning discharges recorded by WWLLN network during Shiveluch volcano eruption on June 16, 2017 [3].

If we compare the systems mentioned above, we should note that lightning discharge detection by WWLLN network relatively the NLDN network is $\sim 10 \%$ at discharge currents of $>25 \mathrm{kA}$ and $\sim 35 \%$ and more at $130 \mathrm{kA}$. In volcano explosive eruptions, the discharges with the currents of $<75 \mathrm{kA}$ form the majority. Thus, it is not possible to rely on the data of WWLLN global network to monitor EC propagation, but it makes sense to apply the network data to check the presence of a lightning in the region [4].

For the VDLS to function properly, high accuracy of timing at all basic station and dense station network are required. Based on that, the method is not suitable for constructing a local network.

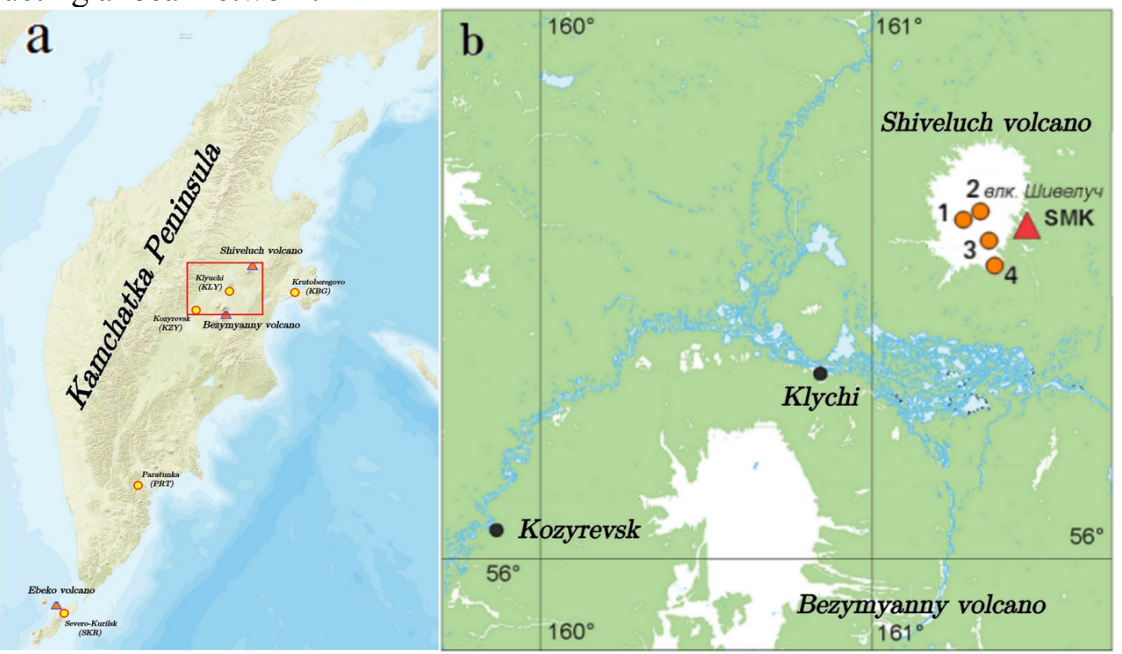

Fig. 1. Location of VLF direction finder (IKIR FEB RAS) and Shiveluch volcano in Kamchatka (a), observation points for volcanoes (CF FITS EGS RAS) in the region of the Northern group of volcanoes and discharge centers recorded by WWLLN (b).

Single-site direction finding method was chosen as the basic one to construct a local network. This method consists in the determination of an azimuth of TEM (Transverse Electromagnetic) wave arrival based on separately recorded field components. Basic station is an antenna system composed of two mutually perpendicular frame magnetic and one rod electric antennas, signal transfer and processing systems. For the network to function at the 
location accuracy of $\sim 500 \mathrm{~m}$ in the radius of $1000 \mathrm{~km}$ from the stations, three observation sites with the base up to $300 \mathrm{~km}$ are required. In this case the time convergence accuracy should not be more than $100 \mu \mathrm{s}$ [5].

\section{Description of basic stations and method}

A basic station includes:

1. antenna system composed of two mutually perpendicular multi-turn frame antennas oriented according to the cardinal points and a vertical rod electric antenna;

2. pre-amplifiers located directly by the antenna bases;

3. matched cable line for analogue signal transmission;

4. analogue-to-digital transducer;

5. microcomputer;

6. software complex for digital data processing.

As long as the directivity pattern of frame antennas is a «right figure eight», it allows us to record EMW components separately. Owing to this, it is possible to reconstruct the projecion of pulse radiation energy flux density vector. Fig. 2 illustrates a signal in three separately recorded field components.

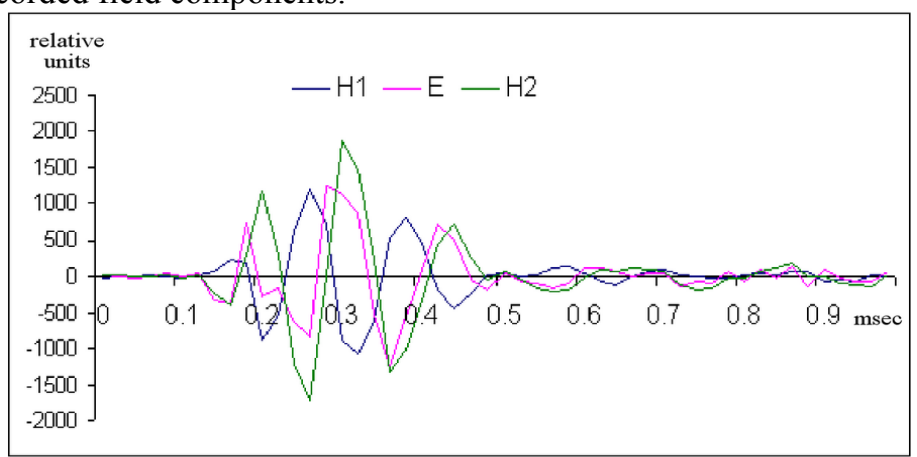

Fig. 2. An record example of a signal from a lightning source: H1 component is North-South, H2 component is East-West, $\mathrm{E}$ is the vertical component of electromagnetic field.

Applying the Fourier discrete transform algorithm, we determine electromagnetic field component amplitudes and phases. Then, for the frequencies, the amplitudes of which exceed the background, polarization ellipse phase portrait is determined. After that, taking into account the field Ez component oscillation phase, the recorded radiation arrival azimuth is found. This method is described in detail in $[5,6]$.

\section{Preliminary results}

Electric processes during volcano eruptions in Kamchatka have been investigated before without local network for lightning discharge observations. For example, Shiveluch volcano explosive eruption was recorded for the first time on October 27, 2010 in real-time mode according to the WWLLN network data (http://wwlln.net/volcanoMonitor.html). A detailed description of Shiveluch volcano eruption development in November 2014 is given in $[6,7]$. Stratification and further propagation of the plume at two heights are illustrated. However, there are no systematic observations of geophysical parameters associated with generation and development of lightning activity during Kamchatka volcano eruptions due to the absence of an observation network.

Shiveluch volcano eruptions also occurred in May-June 2017. Separate lightning discharges near the volcano were recorded by WWLLN (Fig. 1b) and more complete 
information on lightning discharge dynamics was obtained by a VLF direction finder located at Karymshina site.

Fig. 3 shows the dependence of electromagnetic pulse counting rate based on the radiation observations by the VLF detector. Electromagnetic pulses were recorded from the azimuthal directions of $25.6^{\circ} \pm 10^{\circ}$ (Fig. 3a). They coincide with the direction to Shiveluch volcano. It is clear from Fig. $3 b$ that the thunderstorm first phase is observed just after the beginning of the eruption. It is characterized by sharp increase of electromagnetic pulse number followed by a sharp decrease. The first phase lasted from 2 to 5 minutes and then, after a relatively calm period from 1 to 3 minutes, the second longer phase took place. It was accompanied by pulse counting frequency increase. The 2-nd stage duration (Fig. $3 \mathrm{~b}$ ) was about half an hour. The eruptions were confirmed by explosive earthquake records (Fig. 3c). Two-stage volcanic thunderstorm was observed during volcano eruptions in Alaska (Augustine volcano in 2006 and Redoubt volcano in 2009) [8, 10] which showed that the thunderstorm first stage is associated with volcano eruption beginning and formation of an eruptive column owing to the hot ash-gas mixture ejection into the atmosphere. And the second stage is associated with eruptive cloud formations at the tropopause height and their wind transfer.

a)

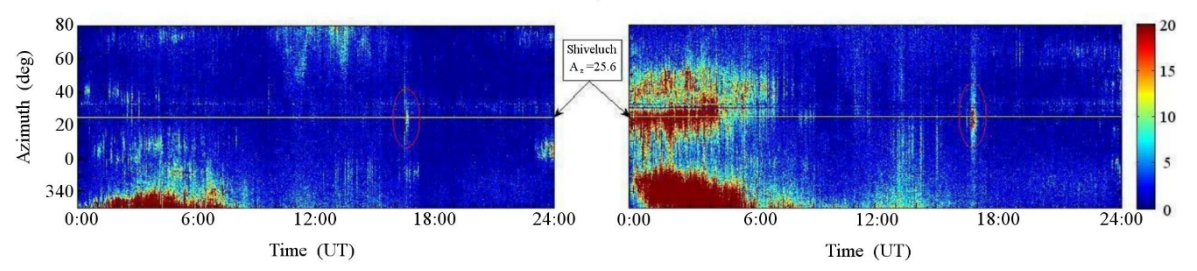

b)

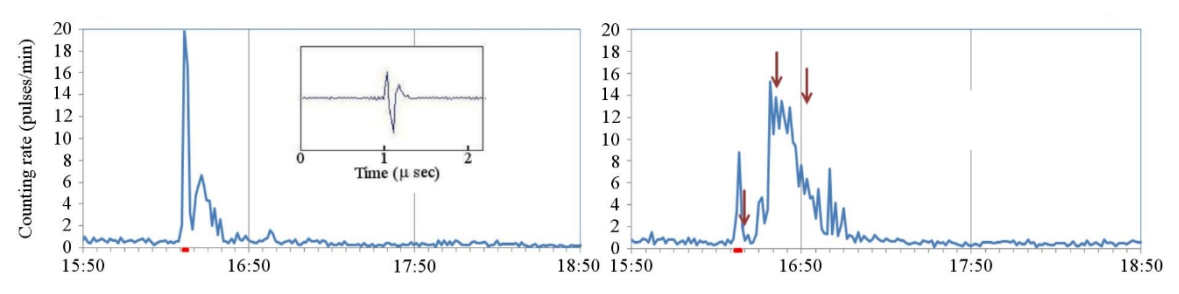

c)

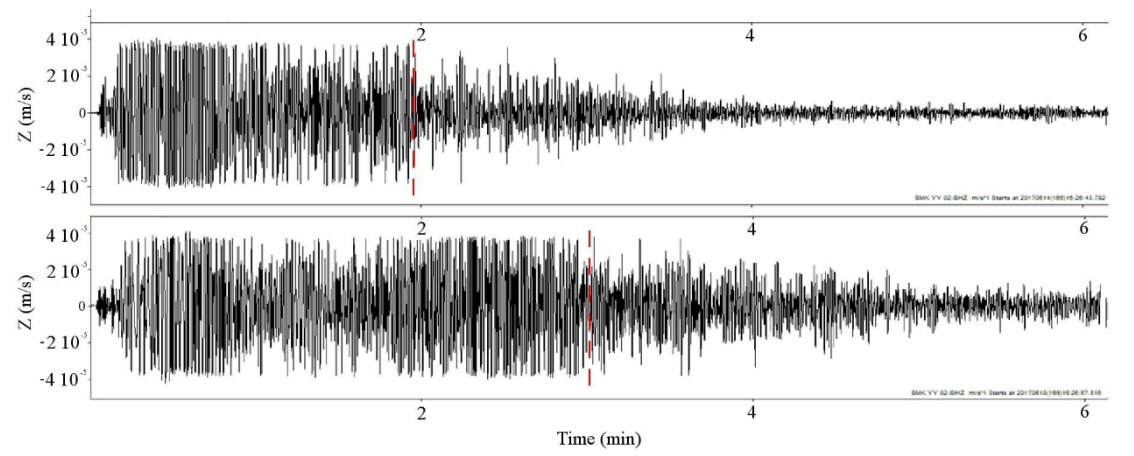

Fig. 3. a - EMP counting rate in the angle interval of $0.1^{\circ}$ from the sector with the azimuth of $340^{\circ}$ $80^{\circ}$ (left 14.06.2017, right 18.06.2017); b - EMP counting rate from the azimuth to Shiveluch volcano $-14.3^{\circ}-32.7^{\circ}$ (left 14.06.2017, right 18.06.2017), the arrows show the times of lightning recorded by WWLLN. The inset illustrates EMP form; $\mathrm{c}-$ ground shift velocity of the vertical component at RTSS SMK (up 14.06.2017, down 18.06.2017). 


\section{Conclusions}

Thus, to investigate volcanic thunderstorm activity sources, a local network is being developed to observe lightning discharges near the Northern group of active volcanoes on Kamchatka peninsula. Creation of a local network will allow us to investigate electromagnetic processes associated with volcanic activity in detail, to develop remote methods for environment sounding, to monitor weather system states in the lower and upper layers of the atmosphere, to investigate the possibility of increase of thunderstorm activity during volcano explosive eruptions.

\section{References}

1. K.L. Cummins, M.J. Murphy, IEEE Transactions on Electromagnetic Compatibility, 51, 3 (2009)

2. Dowden R.L., Brundell J.B., Rodger C.J. VLF lightning location by time of group arrival (TOGA) at multiple sites //J. Atm and Solar-Terr. Phisics, 64(7), 817-830 (2002)

3. P.P. Firstov, R.R. Akbashev, R. Holzworth, N.V. Cherneva, B.M. Shevtsov, Izvestiya, Atmospheric and Oceanic Physics, 53(1), 24-31 (2017)

4. S.F. Abarca, K.L. Corbosiero, T.J. Galarneau, J.Geophys. Res, 115, D18206, doi: 10.1029/2009JD013411 (2010)

5. G.I. Druzhin, Istoriya nauki i tekhniki, 8, 59-66 (2017) (In Russian)

6. G.I. Druzhin, N.V. Cherneva, A.N. Mel'nikov, Russian Meteorology and Hydrology, 36(7), 447-452 (2011)

7. B.M. Shevtsov, P.P. Firstov, N.V. Cherneva, R.H. Holzworth, R.R. Akbashev, Nat. Hazard Earth Syst. Sci., 3(16). 871-874, doi:10.5194/nhessd-16-871-2016 (2016)

8. S.A. Behnke, S.R. McNutt, Bull Volcanol., 76(847), 2-12, doi:10.1007/s00445-0140847-1 (2014)

9. A. J. Bennett, P. Odams, D. Edwards and Ю. Arason, Environ. Res. Lett., 5, 044013 (2010)

10. S.A. Behnke, R.J. Thomas, P. R. Krehbiel, and S. R. McNutt, Eos, 93(20), 15 May (2012) 